\title{
The Political Economy of Deep Decarbonization: Tradable Energy Quotas for Energy Descent Futures
}

\author{
Samuel Alexander * and Joshua Floyd \\ Melbourne Sustainable Society Institute, University of Melbourne, Melbourne 3010, Australia; \\ josh@joshfloyd.com \\ * Correspondence: s.alexander@unimelb.edu.au
}

Received: 14 July 2020; Accepted: 17 August 2020; Published: 19 August 2020

check for updates

\begin{abstract}
This paper reviews and analyses a decarbonization policy called the Tradable Energy Quotas (TEQs) system developed by David Fleming. The TEQs system involves rationing fossil fuel energy use for a nation on the basis of either a contracting carbon emission budget or scarce fuel availability, or both simultaneously, distributing budgets equitably amongst energy-users. Entitlements can be traded to incentivize demand reduction and to maximize efficient use of the limited entitlements. We situate this analysis in the context of Joseph Tainter's theory about the development and collapse of complex societies. Tainter argues that societies become more socio-politically and technologically 'complex' as they solve the problems they face and that such complexification drives increased energy use. For a society to sustain itself, therefore, it must secure the energy needed to solve the range of societal problems that emerge. However, what if, as a result of deep decarbonization, there is less energy available in the future not more? We argue that TEQs offers a practical means of managing energy descent futures. The policy can facilitate controlled reduction of socio-political complexity via processes of 'voluntary simplification' (the result being 'degrowth' or controlled contraction at the scale of the physical economy).
\end{abstract}

Keywords: Tradable Energy Quotas (TEQs); deep decarbonization; renewable energy; post-carbon; carbon budget; epistemic humility; energy descent; Tainter; voluntary simplification; degrowth

\section{Introduction}

In this paper we offer a new analysis of the policy of Tradable Energy Quotas (TEQs), developed by David Fleming [1]. The TEQs system involves rationing fossil fuel energy use for a nation on the basis of either a contracting carbon emission budget or scarce fuel availability, or both simultaneously, distributing budgets equitably amongst energy-users. The goal is to equitably meet climate change mitigation targets [2] and/or fossil energy depletion realities [3,4] within a nationally-agreed and cooperative framework, in a manner 'green growth' strategies seem unable to achieve [5].

While TEQs is designed to manage the contraction of fossil fuel energy use, the system itself is agnostic with respect to the availability of energy from other sources, namely, renewables and nuclear. Given the dependence of all economic activity on having sufficient energy available, and the tight correlation between energy use and Gross Domestic Product (GDP) [5], the implementation of a TEQs system would be expected to incentivize reduced energy demand and/or increased demand for energy from lower carbon sources. All else being equal, the desired rate of increase in energy from alternative sources might be expected to correspond with the rate of decrease in fossil energy use that the TEQs system is intended to deliver. The relationship between demand for lower carbon sources and the means for satisfying this demand is, however, mediated by factors outside the TEQs framework itself. A TEQs system would meet its design objective if fossil fuel energy use was reduced by the intended 
amount, regardless of the portfolio of energy source substitution and demand reduction measures collectively adopted to achieve this.

The extent to which alternative lower carbon sources can meet energy expectations formed in the context of fossil fuels is subject to major uncertainties. It is highly plausible though that such sources will not be able to fully replace the range and scale of energy services currently available [6]. Such a view provides essential context for the present analysis. We note the original design of the TEQs system was informed by a similar outlook, and in this respect our analysis can be considered consistent with the system's underlying ethos [1]. Considering this deeper background, TEQs can be seen not only as a system for managing fossil fuel energy contraction, but as a framework for navigating overall 'energy descent'. Such energy descent would not, however, be a consequence of managing the reduction in fossil fuel energy use via a TEQs system specifically, but a general consequence of transitioning away from fossil fuels by any means, under circumstances in which energy supply from other sources is constrained in its capacity to deliver energy services at an equivalent rate.

Given the plausibility of supply-constrained energy descent as a consequence of the transition away from fossil fuels-a premise we unpack in greater detail below-any implementation of TEQs needs to be considered alongside the economic and socio-political implications of contracting overall energy availability. Even in the event, though, that non-fossil fuel energy supply does not constrain the rates at which energy services are available to future societies, the relevance of considering energy descent is not invalidated. While climate change and fossil fuel resource depletion delimit the scope for energy services enabled by fossil fuels, these are only the two most prominent dimensions of the three-pronged energy dilemma faced by human societies. Alongside these two issues is the broader suite of impacts on biospheric integrity resulting from the scale of physical power presently exercised by humans $[7,8]$. All such exercise of power entails the transformation and transport of matter, resulting in impacts on processes essential to biospheric functions. The complexity of these processes means that control over the consequences of the physical power that humans wield is limited. Human activity throughout history and pre-history has had unintended consequences, whether directly related to intended effects, or as a result of second-order co-effects. These unintended consequences are amplified in proportion to the physical power that directs human activity. If lower-carbon energy sources do in fact support ongoing growth in aggregate energy services, then the scale of impacts on the biosphere will also grow, with limits other than those related to atmospheric greenhouse gas concentration coming into play. With the global material footprint of human societies already greatly exceeding what some investigators consider to be sustainable [9], the implication is that not only must the rate of fossil fuel use be reduced, but so must the total rate at which energy services affect changes in the biosphere, regardless of the primary energy source.

On this basis, we situate our analysis in relation to Joseph Tainter's theory about the development and the collapse of complex societies [10]. Tainter's theory is predicated on the observation that societies become more socio-politically and technologically 'complex' as they solve the problems they face and that such complexification necessitates increased energy use. For a society to sustain itself, therefore, it must secure the energy needed to solve the range of societal problems that emerge. Since problems continually arise, however, there is persistent pressure for growth in complexity [11]. Both historically and today, such 'problems' might include securing enough food, adjusting to demographic, climatic, or other environmental changes, dealing with aggression within or between societies, organizing society and managing institutions, pandemics(!), and so on. Indeed, the challenges any society might face are, for practical purposes, 'endless in number and infinite in variety' [12] (p. 91), and responding to problems generally requires energy and other resources. Tainter describes this development in human organization and behavior as a process of socio-political complexification.

Tainter argues that, due to the diminishing returns on complexity, there comes a point when societies may no longer be able to secure sufficient energy or other key resources to solve the range of problems faced. Accordingly, without corresponding advances in resource-use efficiency, such societies may be unable to maintain arrangements corresponding to their peaks of complexity. Put more 
directly, large-scale societies can collapse (i.e., undergo rapid involuntary reduction in socio-political complexity) when the costs of sustaining their complexity become energetically unaffordable [13]. As outlined below, this is the essential dynamic that Tainter argues 'can explain collapse as no other theory has been able to do' [14] (p. 400). Not only is Tainter's theory of historical interest, we maintain it can offer insight into the evolving nature and dynamics of globalized industrial civilization, today and in the future $[15,16]$.

We will argue that TEQs offers a practical and effective means of managing contraction in the use of energy derived from fossil fuels. Furthermore, it offers an important policy tool to help navigate the overall trajectory of energy descent that will plausibly follow from such contraction. TEQs could therefore act as a vital support for the controlled reduction of socio-political complexity via processes of 'voluntary simplification' and economic 'deintensification' (the result of these processes being 'degrowth' or controlled contraction in the scale of the physical economy $[17,18])$. We therefore distinguish voluntary simplification from the similar term 'voluntary simplicity', with the latter generally referring to individuals consuming less within existing structures, and the former referring to a reconfiguration of systems and structures to manage, or actively induce, reduced socio-economic complexity [19]. Structural voluntary simplification, in this sense, would likely require cultural voluntary simplicity, but the converse need not be true.

Under conditions where current levels of socio-political complexity cannot be extended or even maintained, acknowledging the systemic and cultural need for such controlled reduction is, we argue, far preferable to allowing collapse to unfold haphazardly and chaotically, but making this case requires a nuanced engagement with Tainter's theory. For present purposes, we will treat voluntary simplification and economic deintensification as aspects of a general process leading to degrowth of formal economies and socio-political matrices, although to emphasize Tainter's conceptual framework we will generally refer to this process via the term 'voluntary simplification'. Defined further below, this refers to a process of planned contraction of a society's energy and resource demands, with corresponding reductions in socio-political complexity $[17,18]$.

\section{Structure and Overview}

Our substantive analysis begins in Section 2 by reviewing the literature on renewable energy (RE) transitions. We seek to understand the scope for RE to replace the extent and nature of energy services provided by fossil fuels, a question of urgency for existing economic systems due to both climate change and the finitude of fossil fuels. We proceed from a position of epistemic humility [6]-that is, from an appreciation of deep uncertainties surrounding energy futures, and therefore of what knowledge claims relating to this area of investigation can reasonably be made in the present. These uncertainties imply the need to hold serious doubts about whether RE (or nuclear) can fully replace what it is that human societies do at present via fossil fuels. While we fully endorse the goal of transitioning to RE, we contend it is plausible that a full transition would entail 'energy descent' relative to the availability of energy services in developed regions of the world today [20-24]. Given that the degree of socio-political complexity, in Tainter's sense, that can be maintained by a society is dependent on available resources, reduced energy availability is likely to drive significant deintensification of economies, and with this, reduction in socio-political complexity, whether enforced through circumstances that overwhelm human agency, or voluntarily embraced $[19,25]$. As discussed in the introduction, even if energy services are not supply-constrained, other biosphere impacts resulting from continued exercise of physical power at the current historically extreme level must at some point force a confrontation with the need for contraction in human energy conversions, and hence with the prospect of reducing socio-political complexity. The term 'deintensification' implies changes that generally result in closer proximity between producers and consumers of goods and services, both geographically and socially. This will typically involve the emergence or reemergence of informal economies at the bio-regional, neighborhood, and household scales, where mostly local resources are used to provide for mostly local 
needs, at the expense of formal economic transactions and arrangements where global supply chains coalesce in complex and often energy-intensive ways [1].

Given the epistemic grounds on which anticipation of energy futures rests, energy descent is no less plausible (and a sound case can be made that it is more so) than alternatives. Individuals, households, nations, and indeed the global community should therefore plan for such an outcome, even if this conflicts with dominant expectations of continued economic growth and corresponding assumptions about the need or desire for ongoing increases in socio-political complexity [26]. In Section 3 we explore the implications of energy descent informed by Tainter's theory of complexity and collapse. Although we sympathize with much of Tainter's analysis, we seek to show that energy descent pathways involving voluntary simplification and economic deintensification are potentially more viable than is suggested if the historical record is taken as the necessary benchmark. That is, we suggest that pathways may be available differing sufficiently from those attempted previously to make economic deintensification a legitimate policy option for decision makers. In that vein, we outline how a society embracing voluntary simplification could manage energy descent in ways consistent with human and ecological flourishing, although we argue this means deep transformations in societal structures, cultures, and institutions $[17,27]$, not merely attempting to 'green' today's globalized carbon civilization [5].

To anticipate later discussions, energy descent futures shaped by voluntary simplification would involve more localized agency in relation to governance and organization (i.e., more context-specific, context-sensitive, and hence more diverse social forms and structures across bio-regions and cultures); it would require planned contraction of energy and material demands (i.e., degrowth); it would necessitate a more equitable distribution of wealth; and it would involve embracing cultures of consumption that reflect ethics favoring sufficiency, moderation and frugality. While the likelihood of voluntary simplification, economic deintensification and consequent degrowth receiving population-wide embrace may not be high, we argue these strategies deserve critical attention, especially since we contend that they are the best, and perhaps the only, means of resolving the overlapping crises facing humanity today $[13,16,28,29]$.

In Section 4, we outline TEQs as a policy tool with practical potential to manage society-wide processes of energy descent in viable and equitable ways. We conclude with brief reflections on obstacles and challenges that lie in the way of TEQs (and other strategies for managing energy descent) being adopted.

\section{Energy Descent as a Post-Carbon Transition Scenario}

In mainstream energy discourse $[30,31]$ the fact that fossil fuels are finite and being depleted at pace is generally treated as a future concern that will be solved before it arrives-put simply, demand will peak before supply. Climate change, on the other hand, is increasingly recognized as a serious threat, but again the prevailing view seems to be that mitigating and adapting to climate change via deep decarbonization (supported by negative emissions technologies) will be difficult but manageable. In support of this energy and climate optimism, analysts point to promising advances in technology (e.g., solar photovoltaic (PV), wind turbines, batteries, electric vehicles, etc.) and efficiency improvements (i.e., 'cleaner production'). Furthermore, in an age governed by neoliberal rationality [32], the dominant policy response is to maintain that markets and price signals will provide the right incentives to drive an optimal energy transition beyond fossil fuels without facing energy shocks or dangerous climate change. 'Optimal transition', in this sense, means minimum impact on GDP relative to conventional growth expectations in the absence of climate change mitigation efforts. From this techno-optimistic view, the growth paradigm of global capitalism is up to the task and system change is not necessary.

Even if such techno-optimistic and pro-market views are by no means universal, media and political narratives both reflect and propagate the widespread and popular assumption that renewable energy (or nuclear power) will be able to replace current fossil fuel use and mitigate climate change without significant social or economic disruption, as well as match growing global energy demand 
into the distant future. More specifically, there seems to be a widespread assumption that post-carbon energy sources are consistent with a socio-politically complex, globalized economy that is structurally designed or required to grow without limits [33]. Moreover, the fact that continued expansion in the scale of energy services will almost certainly be attended by increasing biospheric disruption and damage receives essentially no attention within orthodox energy and economic futures discourse.

Foundational in this view is the assumption that low-cost final energy carriers will be even more abundant in the future than today $[30,31,34]$. This is not always a conscious assumption. Rather, in large-scale, complex societies, the association between institutional responses to collective problems and increased energy demand is rarely apparent. Citizens of societies organized by industrial economies and market capitalism have simply become accustomed to overcoming (or at least displacing) any immediate problem that arises, and, simultaneously, to satisfying the aggregate growth in energy demand.

In contrast, the alternative energy narrative we outline in this section maintains that we should be preparing for futures not of energy abundance, but rather of reduced energy availability. With respect to the most energy intensive societies, this means planning for 'energy descent', a term we borrow from permaculture theorist and practitioner, David Holmgren [35]. While acknowledging a range of uncertainties about how humanity's energy futures will unfold, our review of the literature $[6,36]$ supports the view that energy descent is not only highly plausible, but that there is no epistemically sound basis for treating this as simply a 'high-impact but relatively low probability' outcome of the transition away from fossil fuels (see also, [20-24]]. This implies that planning and preparing for such futures should be given far greater weight in energy transition praxis than is presently the case.

\subsection{Fossil Fuel Depletion, Climate Change Mitigation and Preservation of Biosphere Function as Drivers of Energy Descent Futures}

The dominant narrative of energy abundance can be questioned from three principal angles. First, we could begin by acknowledging that fossil fuels-currently comprising about 84 percent of global commercial primary energy use $[6,37,38]$ —are finite, and therefore today's carbon-based civilization, one way or another, has a time limit [23]. Humanity's one-off fossil energy inheritance is but a brief anomaly in the evolution of the human story, a momentary energy spike when considered in context of our species' deep history [39].

Although analysis aimed at anticipating the timing and trajectory of fossil energy depletion is subject to numerous sources of uncertainty, the fact that fossil fuels are finite and subject to depletion is an undeniable geological reality. This is a matter of particular significance in relation to oil [40], given its role in enabling industrial agriculture, and global transport systems and supply chains. As the low-hanging fruit is picked, it becomes harder to increase or even maintain current net energy supply [41].

In recent years, the large growth in United States oil production due to shale oil developments using hydraulic fracturing techniques has encouraged some commentators to proclaim 'the death of peak oil'. More careful analysis of the evidence suggests that such pronouncements are greatly exaggerated. Eventually, perhaps sooner than most think [3], the rate of oil production will enter a phase of net energy decline, with new discoveries unable to offset the flagging fortunes of existing assets [42]. Despite large oil resources remaining relative to historical production, the economically recoverable proportion of the overall resource is subject to headwinds including increasing production costs and price volatility, as low prices impact the viability of commercial producers [43].

While oil has commanded the majority of attention to date in public discourse about fossil energy resource depletion, the timelines for gas and coal may not be nearly as protracted as is typically assumed [3]. Alongside this, exponential growth trends (both energetic and economic) that have defined dominant conceptions of human development throughout the industrial era can be expected to end, and even reverse. Without attempting a comprehensive review here, in our other work [36] we 
have analyzed the oil situation and provided an evidential case for the ongoing relevance of 'peak oil' dynamics based on the following ten points (see also [3,4]):

- Excluding the US and Canada, the rest of the world has had flat oil production since 2005.

- There are deep uncertainties over the economic viability of US shale production (especially given unstable oil markets and low prices as a consequence of the COVID-19 pandemic)

- Oil discoveries are at record low and production decline rates are increasing

- Energy-return-on-investment is in terminal decline

- The oil industry is facing major financial challenges, which will be compounded as the emerging climate change response renders as 'stranded assets' much of the fossil fuel production, processing and distribution infrastructure currently in place

- $\quad$ Lack of oil investment due to low prices

- Oil exports (from the remaining oil exporting nations) seem to have peaked, meaning the oil importers should not expect to maintain or grow their share of oil supply

- Failed states and geopolitical disruptions are an ever-present threat to oil supply

- A robust climate response means we should be 'choosing' peak oil now (see carbon budget analysis below)

- Current oil consumption patterns are incompatible with fair distribution of remaining fossil fuels in a global economy characterized by extreme wealth inequality.

Challenges of such nature raise questions not only about what a post-carbon world will look like, but, perhaps more pressingly, how we should best manage the inevitable and foreseeable contraction of fossil fuel production in coming years and decades.

Compounding this challenge of maintaining energy supply in the face of fossil energy depletion, climate science overwhelmingly concludes that the burning of fossil fuels is a leading cause of anthropogenic climate change [2]. Any adequate response to this potentially existential threat is going to require, among other things, a swift and committed transition beyond fossil energy sources (i.e., deep decarbonization).

The best available science confirms that to keep the impacts of climate change within the range of human adaptation, consumption of fossil fuels must be limited even before limits are geologically enforced. A recent United Nations report [44] concludes that to keep global temperature rise within $1.5^{\circ} \mathrm{C}$ of the pre-industrial baseline, globally humanity needs to decarbonize by $7.6 \%$ p.a. between 2020 and 2030. More challengingly still, Anderson et al. [45] argue that the most developed nations need to decarbonize by $14 \%$ p.a, starting now, to achieve pathways compliant with the Paris Agreement. In 2019, global emissions crept upwards again, and it appears that even a global economic crisis triggered by a pandemic will force only modest emission reductions. At time of writing in mid-2020, the International Energy Agency (IEA) projects that the economic shutdown in response to COVID-19 might reduce emissions by 'merely' 8 per cent in 2020 [46].

Even ignoring fossil fuel depletion then, the socio-economic challenge of decarbonizing by between $7-14 \%$ p.a. (depending on assumptions and focus) is profound. Some of the decarbonization needed will be achievable through efficiency gains, but to think that the developed nations can decarbonize by $14 \%$ p.a. through efficiency increases for years on end, while also maintaining economic growth, is a dangerous fantasy $[5,6,47]$. While efficiency gains must be pursued, staying within carbon budget targets requires that socio-economic structures be adjusted in ways that use less energy. Energy descent, whether a consequence of fossil fuel depletion, climate change mitigation, or both, should now be treated as an uncontroversial feature of the plausible futures envisaged by decision makers in orthodox institutions everywhere. An important task now for communities is to construct images of preferred futures in which energy descent is accepted as a basic contextual feature. Here, energy efficiency becomes a subordinate concern to energy sufficiency as an orienting value [48].

Finally, continued exercise of physical power at the extreme rates associated with current global energy service provision must ultimately intersect with limits associated with the disruption or damage 
to essential biosphere functions. All energy conversions entail environmental impacts. The impacts scale with the aggregate global rate of energy conversion [23,28]. Even in the absence of further climate impacts resulting from greenhouse gas emissions, energy use enabled by natural environmental energy flows that on human timescales can be considered inexhaustible will eventually, if not already, encounter limits associated with the biosphere's capacity to absorb or tolerate impacts imposed on it $[8,9,13,16,28]$.

\subsection{Differentiating Fossil Fuels and Post-Carbon Energy Sources: Epistemic Humility Regarding Energy Transition Supports Energy Descent Planning}

This brief review of humanity's situation through the overlapping contextual lenses of fossil energy resource depletion, carbon budget analysis, and biosphere functionality sets the scene for a further context of inquiry. This concerns the extent to which alternative energy sources and conversion technologies-specifically RE and nuclear power-will be able to replace the energy foundations of today's globalized, fossil fuel-based civilization.

Contemporary energy transition studies is an area of scholarly debate in which competing schools of thought, e.g., 'renewable advocates' vs. 'nuclear advocates', hold what can seem to be commitments of an almost religious nature to particular energy solutions [49]. While we cannot review the intricacies of this debate here [6,20-24], we approach the issues with more circumspection, knowing that the current knowledge basis for energy transitions is uncertain, that reasonable, evidence-based analysis can support divergent views on the best path forward. However, we maintain that this very uncertainty about the viability of fully replacing fossil fuels with alternative sources, and the epistemic humility this uncertainty demands, ends up supporting the case for energy descent preparation and planning. That is, if thoughtful, critical analysis supports contradictory views about whether renewable energy or nuclear power will be up to the task of fully replacing the energy services provided via fossil fuels, broader society should not assume existing energy supply—and the societal complexity it enables—can be maintained in a post-carbon world.

Even for energy analysis with a techno-optimistic orientation that leads to high confidence in the ability of RE to fully replace the energy services provided by fossil fuels, it remains the case that the greater the demand for energy services, the lower the likelihood that RE can meet that demand. As demand expectations decrease, the likelihood increases. The fundamental practical point, with respect to energy-intensive societies, is that it would be better to organize and prepare for reduced energy demand, because the less energy needed, the more readily any transition to $100 \% \mathrm{RE}$ will be realized.

The case for epistemic humility can only be emphasized further when one looks at the real world to see how slowly the renewable energy transition has advanced in recent decades. The world knew enough about fossil fuels and climate change in 1988 to establish the IPCC, but in the last thirty years, very modest progress has been made on the post-carbon transition. Wind, solar and geothermal together provided merely between $1.7 \%$ [50] and 4.1\% [38] of global primary energy supply in 2019, depending on energy accounting convention. A transition to $100 \% \mathrm{RE}$ is likely going to be more difficult, slower and almost certainly more expensive than is typically thought to be the case. It follows that it would be prudent to prepare for energy descent futures.

Adding further to the scope of the decarbonization challenge is the perennial question of 'who benefits?' This involves making distributive assessments or evaluations about how the energy humanity manages to harness should be shared amongst the growing global human population, currently at 7.8 billion and trending toward 11 billion or more by the end of the century [51]. This is the ethical dimension that energy transition inquiries too often marginalize or simply ignore altogether, in favor of technological and market-driven solutions. In short, if usable energy is scarce, then energy-intensive societies especially need to ask whether they can justify their high demands if that means poorer societies are left in varying degrees of energy poverty. 
Elsewhere we have provided an evidential case for energy descent in much more detail $[6,36]$. For present purposes, our contention is simply that there are various reasons to think that the future may be shaped by energy descent not energy abundance. Fossil fuels are finite and being depleted at pace; climate change mitigation cannot be solved merely by 'greening' energy supply but also requires choosing radical energy demand reductions; nuclear and renewables probably cannot fully or directly replace the nature and magnitude of fossil energy surpluses; the earth's biosphere has finite capacity to absorb or tolerate the impacts of the physical power exercised by human societies and finally, distributive concerns suggest that energy-intensive societies should be reducing their energy use in order to share global energy access more broadly. Any one of these energy challenges justifies taking energy descent futures seriously. Considered together, we contend that energy descent futures are more likely than not. While this statement is subject to the same circumspection that we argue should apply to contrary findings, we contend that energy descent futures, which are presently marginalized [52], should be elevated from a peripheral concern to one that actively shapes the ways in which actors engage in energy transition praxis.

The space available here precludes comprehensive treatment of this case. Our aim instead is to unsettle some assumptions about energy futures that today seem to be widely held with undue confidence. Such an act of unsettling can prepare the way for developing perspectives on energy futures that better equip humanity to find viable pathways amongst the landscape of emerging global challenges.

\section{Tainter's Theory of Societal Complexification: Exploring Voluntary Simplification as an Alternative to Collapse}

It is not necessary to resort to energy determinism or crude reductionism to insist on the fundamental role energy has played, and continues to play, in shaping the rise (and demise) of large-scale societies [39]. Energy is not just another resource or commodity: it is the key that unlocks access to all other resources and commodities, thereby giving shape to the physical boundaries within which human societies must take form. In other words, a society's energetic foundations delimit the socio-economic forms that it may take. This is simply to concede that a particular form of society cannot emerge without sufficient energy supplies, in the appropriate forms, to support it, and further, that a society must be able to meet its ongoing energy demands if its specific socio-economic form is to persist. If it cannot, the society will transform or be transformed, voluntarily or otherwise.

In this section we analyze the role of energy in large-scale societies through the lens of Tainter's theory of socio-political complexification and collapse [10], focusing especially on what energy descent futures could mean for the current growth-orientated and globalized industrial civilization. We begin with a brief account of the theory, then critically assess the prospects that it leaves open for managing energy descent via the strategy of voluntary simplification.

\subsection{Overview of Tainter's Theory of Complexity}

In his seminal work, The Collapse of Complex Societies, Tainter presents an original theory of social complexification and its maintenance that he offers as the best explanation for the collapse of human societies throughout history [10]. Tainter defines social complexity in terms such as the number of distinct roles that a society incorporates in coordinated ways so that the roles cooperate as a functioning whole [10] (p. 23). According to Tainter, societies increase in complexity in order to solve collective problems that arise as a consequence of present ways of organizing their affairs and producing the goods and services on which they rely. For example, solutions to problems might involve developing technical abilities, establishing new institutions, diversifying social, economic, and political roles, as well as increasing production and information flows, all of which require energy and resources.

Tainter's central thesis is that while increasing social complexity initially provides a net benefit to a society, eventually the benefits derived from complexity diminish and the relative costs begin to increase. The diminishing returns on complexity arise from the fact that, when trying to solve 
societal problems, 'inexpensive solutions are adopted before more complex and expensive ones' [12] (p. 26), meaning that over time the energy and resource costs of problem-solving tend to increase and the relative benefits decrease. As the overall pool of opportunities available for increasing the productivity of systems is exploited, the remaining scope for further increase diminishes, and a given increment of increase becomes more costly. As the marginal returns on investment in complexity continue to diminish for some area of activity, there comes a point at which these returns become negative, and further investment leads to declines in the overall return that the activity produces. When all the energy and resources available to a society are required just to maintain the society, further problems that arise cannot be solved and the society then enters a phase of decline, or even rapid collapse. That is, societies can be destroyed when the costs of sustaining their complexity become unaffordable in terms of resources in general, and energy resources especially.

One of the most challenging aspects of Tainter's theory is how it reframes-one might even say revolutionizes-sustainability discourse [53,54]. Tainter argues that sustainability is about problem solving and that problem solving increases social complexity. However, he also argues that social complexity requires energy and resources, and this implies that solving problems, including ecological problems, can actually require increases in energy and resource consumption, not reductions. Indeed, Tainter maintains that sustainability is 'not a passive consequence of having fewer human beings who consume more limited resources' [54] (p. 93), as many argue it is. In fact he suggests that 'voluntary simplification' - which refers to the pursuit of forms of social organization that remain viable with reduced resource use-may no longer be an option for industrial civilization [12]. Instead, Tainter's primary conception of sustainability involves subsidizing ever-increasing complexity with more energy and resources in order to solve ongoing problems. We say 'primary conception' because there are subtleties in Tainter's position that leave open theoretical space for alternative conclusions and pathways.

Here we critically examine Tainter's contention that voluntary simplification is not a viable path to sustainability. In fact, given the plausibility of future energy descent (see Section 2), we argue that voluntary simplification is by far the best strategy to implement, even if the chances of adoption in the current political and cultural climate-a climate which promotes growth in consumption, material affluence, and technological advance as pre-eminent societal values-do not provide grounds for much optimism.

Part of the theoretical tension between our position and Tainter's critique of voluntary simplification turns on differing notions of 'sustainability'. Whereas in Tainter's sense sustainability infers sustaining existing forms of socio-political organization, we extend this to changing the forms of organization through voluntary simplification, insofar as that is required for humanity to operate within the carrying capacity of the planet [17]. Furthermore, even if attempting to sustain existing forms of organizing through ever-increasing complexity continues to be humanity's dominant approach to solving societal problems, we maintain the alternative path of voluntary simplification remains the most effective means of building 'resilience' (i.e., the ability of an individual or community to withstand societal or ecological shocks), and better yet, can lay the foundations for societies to develop the 'antifragile' characteristic of living systems that strengthen in response to stress [55]. This is significant because it justifies the practice and promotion of voluntary simplification, irrespective of the likelihood of it ever being broadly accepted. That is, if an end to industrial civilization's trajectory of increased socio-political complexity is coming one way or another due to energy descent, then it would be better to accept this energetic trajectory and prepare for it, rather than wait for it to arrive through crisis and collapse.

While we accept that problem solving generally implies an increase in social complexity of the nature Tainter describes, the position we present below is that there comes a point when such complexity itself becomes a problem, at which point voluntary simplification, not further complexity, is the most appropriate response. Not only does industrial civilization seem to be at such a point today [56-58], or well beyond it, we hope to show, albeit in a preliminary way, that voluntary simplification presents a viable and desirable option for responding to today's converging social, economic and ecological 
problems. This goes against Tainter's primary conception of sustainability, while accepting much of his background theoretical framework. After unpacking our theoretical position, in Section 4 we discuss Tradable Energy Quotas as a policy tool eminently suited to initiating and managing the voluntary simplification strategy.

\subsection{Critically Analyzing Voluntary Simplification as an Energy Descent Strategy}

The conditions characterized by Tainter under the term 'complexity' typically entail homogenization and standardization of production and management practices, and exercise of control through centralized governance mechanisms. Fleming points out that in important respects such conditions are better characterized as simple rather than complex [1]. In order to appreciate the potential for the approach that we term voluntary simplification to function as an energy descent strategy, some further nuances associated with the concept therefore require unpacking. The relationships discussed below are summarized in Figure 1.

Where the general problem-solving strategy identified by Tainter implies uniting increasingly large territories and polities under common coordination and control mechanisms, voluntary simplification implies decentralization of governance and disaggregation of production systems. This in turn supports developing locally adaptive responses to perennial social challenges, and hence leads to diverse forms of organization, with corresponding increase in redundancy. The outcome of locally initiated and managed voluntary simplification as a means of deintensifying economic systems from the 'bottom-up' can in this respect be viewed as leading to an increase in complexity from a macro-scale, external observer perspective. This macro-perspective complexity is a consequence of many local initiatives developing in parallel, according to the differing circumstances of those enacting them. That this is framed in terms of 'simplification' reflects desires of individuals, families and communities struggling to cope with the demands on their time and attention attending the conditions that Tainter characterizes in terms of increased complexity. Therefore, 'voluntary simplification', rather than being a social-scientific description of the macro societal-level outcome from the processes gathered under its banner, is a descriptor for the collective desire that might unite people within a social movement that could respond in a viable way to the dilemma that Tainter's theory presents.

Uniting within a social movement aimed towards greater local autonomy is different, though, from uniting under a uniform means of social organization. Voluntary simplification requires creation of increased space for local organization and distributed community-level governance of economic processes, consistent with the general principle of subsidiarity. Realizing the benefits of subsidiarity would require that its exercise be allowed via bottom-up civil society organization, rather than formally mandated from the top-down by governments. This implies removing policies, laws and regulations that impede the development of informal economies at the household, neighborhood, community and bio-regional scales. It also means winding back subsidies and policy supports that favor formal economic arrangements, where informal arrangements are sufficient.

A consequence of this is closer or more direct contact between producers and consumers, including greatly increased production of goods and services by the end-consumers themselves [59]. For instance, walking and cycling entail self-production of transport, while greatly reducing the scale of the intermediate economy necessary to provide the services (traffic policing, insurance, infrastructure maintenance, health care) required by personal automobile transport. Even an increase in use of electric cargo bikes can have a major impact here. A more diverse transport system based on better matching modes to specific needs is implied, and can be viewed from the macro-perspective as more rather than less complex, while from the micro-perspective of participants it is experienced as simplification. Similar patterns of deintensification through voluntary simplification can be envisaged in areas including food and fiber production, manufacture of clothing and housing and maintenance and repair of tools and equipment $[1,27]$. 


\begin{tabular}{|c|c|c|}
\hline $\begin{array}{l}\text { Possible trajectories for civic } \\
\text { societies under resource- } \\
\text { constrained conditions }\end{array}$ & $\begin{array}{l}\text { Tainter: societies subject to } \\
\text { decreasing marginal return on } \\
\text { investment in socio-political } \\
\text { complexity as problems are solved }\end{array}$ & 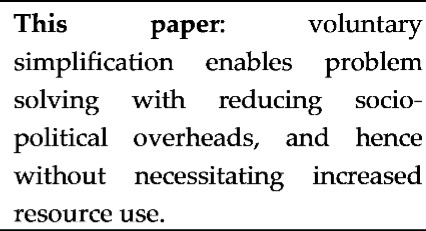 \\
\hline Characteristics & $\begin{array}{l}\text { Proliferation in social roles and } \\
\text { technologies to solve problems, } \\
\text { requiring increased coordination } \\
\text { effort and new governance } \\
\text { institutions. Coordination of } \\
\text { increasingly specialized roles } \\
\text { accounts for a growing proportion } \\
\text { of overall resource use. Sustaining } \\
\text { established social structures and } \\
\text { organization entails ever } \\
\text { expanding resource use. }\end{array}$ & $\begin{array}{l}\text { Increasing proximity between } \\
\text { producers and consumers of goods } \\
\text { and services. Increasing } \\
\text { production of goods and services } \\
\text { by informal economic } \\
\text { arrangements at scales from } \\
\text { households to bio-regions. } \\
\text { Sustaining viable communities by } \\
\text { developing social structures and } \\
\text { forms of organization with lower } \\
\text { formal governance and } \\
\text { administration overheads. }\end{array}$ \\
\hline Inside participant perspective & $\begin{array}{l}\text { 'Complex': Demands for ever } \\
\text { increasing labor productivity with } \\
\text { diminishing marginal returns on } \\
\text { effort, proliferating rules \& } \\
\text { regulations, and necessity of } \\
\text { engaging with increasingly diverse } \\
\text { services result in time pressure } \\
\text { and fragmentation of attention for } \\
\text { individuals, families, civil society } \\
\text { organizations, and work groups. } \\
\text { Balancing ever increasing } \\
\text { competing demands leads to the } \\
\text { experience of life as increasingly } \\
\text { complex. }\end{array}$ & $\begin{array}{l}\text { 'Simple': Production processes for } \\
\text { goods and services, along with } \\
\text { functionality of the goods and } \\
\text { services produced, will be } \\
\text { increasingly transparent from the } \\
\text { inside participant viewpoint. } \\
\text { While individuals may participate } \\
\text { in an increased range of roles and } \\
\text { activities, motivation for this will } \\
\text { be based to a greater degree on } \\
\text { interest, capacity, and capability, } \\
\text { and regulated via individual } \\
\text { sovereignty rather than formal } \\
\text { institutional demands and external } \\
\text { authority exercised from a } \\
\text { distance. }\end{array}$ \\
\hline Outside observer perspective & $\begin{array}{l}\text { 'Simple': Centralized control and } \\
\text { coordination of increasingly } \\
\text { specialized social and economic } \\
\text { functions requires high levels of } \\
\text { standardization and bureaucratic } \\
\text { regulation. While role descriptions } \\
\text { proliferate, work practices involve } \\
\text { increasing uniformity. An outside } \\
\text { observer considering a society as a } \\
\text { coordinated whole will see a } \\
\text { narrow range of repeated patterns. } \\
\text { Homogenization between societies } \\
\text { will also be apparent. }\end{array}$ & 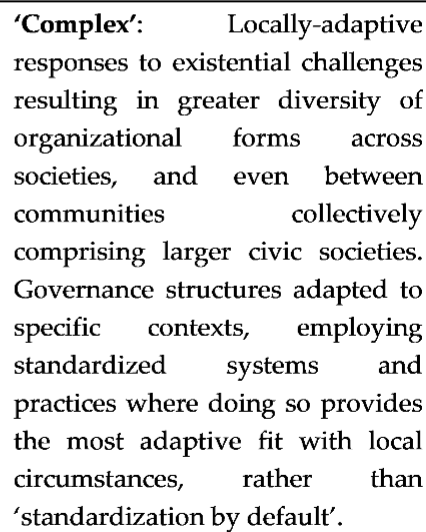 \\
\hline
\end{tabular}

Figure 1. How the experience of different forms of social organization as 'complex' or 'simple' varies between participant and external observer perspectives.

These shifts are occurring already in many locations, but are limited in scope by incentive structures that treat employment in the formal economy as vastly more socially legitimate than work in informal economies. Barriers to greater self-production of transport such as proximity of housing to employment opportunities in the formal economy, norms around working hours and social conventions relating to motor vehicle ownership and access are all amenable to change in concert with moves that give greater status to participation in informal economies. An increase in hours spent working in informal economies at household and neighborhood scale would involve simpler webs of economic production, in the sense of being far more locally bounded than at present $[60,61]$. This would lead though to 
increased diversity patterns of social interaction viewed from the macro-perspective. Whereas the typical trajectory of socio-political complexification that Tainter's model describes leads in the direction of social 'monocultures', economic deintensification through voluntary simplification points towards the emergence of social and economic 'polycultures'. Alongside these changes, overall reductions in resource use could be anticipated [17].

The question remains though of how locally-initiated economic deintensification through voluntary simplification could possibly emerge across societies that are currently configured on lines diametrically opposed to such trajectories. Under what circumstances could voluntary simplification appear sufficiently attractive as a strategy for achieving life satisfaction, for a sufficient number of people, that it might emerge as a major social movement with scope to shift human societies onto sustainable paths? It is with this question in mind that we now turn attention to TEQs.

\section{Tradable Energy Quotas: A Policy Tool for Deep Decarbonization}

\subsection{Overview of Tradable Energy Quotas}

Equitable and just transition to post-fossil fuel societies will entail engaging all sectors of society, and in fact every citizen, in the transition challenge. At the political level, this requires policy instruments that support and influence such a level of engagement, and that enable people to work together towards a common goal. The Tradable Energy Quotas (TEQs) system devised by David Fleming is designed specifically to close the gap that currently exists between the physical reality of energy use impact on climate, and the political reality of social lock-in to the existing economic system [1]. TEQs is intended to engage every member of society in the task of reducing dependence on fossil fuels, on an equal footing.

TEQs would achieve such equitable engagement by putting a hard cap on a nation's emissions from energy use [62]. At the centre of the TEQs system is a national emission budget that sets the quantity of carbon emissions permitted in any year. In the event that supply scarcity constrains fossil fuel availability more tightly than would be the case via the national emission budget, the annual budget would be adjusted accordingly so that the TEQs system adapts seamlessly to the new circumstances.

An equal share, or quota, of the national budget is then freely issued to every adult, collectively covering the share of national emissions accounted for by household energy use. Anyone wishing to use more than their free share must purchase additional units from those using less than theirs, in a market set up for that purpose. All non-household energy users (businesses, service providers, Government entities at all levels) purchase their emission quotas/units by tender in a weekly auction.

A year's supply of TEQs units is issued on the first day of operation. This is topped up on a weekly basis, so that a rolling one-year supply of credits is maintained in participants' accounts. Each TEQs unit represents $1 \mathrm{~kg} \mathrm{CO} 2$ emitted. Fuels and electricity are rated in terms of the quantity of carbon dioxide emitted per metered unit, over each energy unit's full life cycle. TEQs units equivalent to the corresponding emissions are then surrendered whenever fuel and electricity are purchased. The system's designers envisage unit transactions being handled automatically via integration with the existing credit- and debit-card systems for financial transactions [1,62], thereby avoiding the need for a separate 'carbon card'.

\subsection{Why Tradable Energy Quotas Can Manage Energy Descent in Optimal and Equitable Ways}

We are now in a position to return to the question posed at the end of Section 3. Voluntary simplification, we contend, offers a viable strategy for bridging the gulf between current large-scale societies reliant on levels of per-capita resource use so extreme that they undermine their own future prospects, and forms of society that could enable large populations to enjoy decent and rewarding lives while allowing their descendants similar opportunity. At the same time, we recognize that sound reasoning and enthusiastic advocacy have little prospect of moving this beyond a fringe view, while cultural narratives of wellbeing are built on imperatives that either entail directly, or require 
as a condition of their pursuit, ongoing growth in aggregate resource consumption. This places civic leaders, especially in liberal democracies, in an invidious position. Even if the implications of increasing resource consumption for the integrity of the biosphere and continued functioning of human systems are fully appreciated, moves to address this by forcing a shift away from reliance on finite and dangerously polluting resources implies curtailing established and expected freedoms. While the freedoms to use depleting and polluting resources remain unchecked at the population scale, voluntary simplification, which requires self-imposed limits on these freedoms, is even less tenable.

In order for voluntary simplification to become desirable and attractive at population scale, it first needs to be perceived as a pathway to, rather than a constraint on, greater freedoms than are otherwise available. This means that collective mechanisms for limiting the use of depleting and polluting resources must first be in place for voluntary simplification to be effective. Such limits could be either institutionally self-imposed via formal statutes and regulations (as is the case with laws to control pollution), or imposed by biophysical constraints. The latter is evident, for example, in situations where water shortages are imposed on populations through drought, and hence where political-economic power differentials determine relative access to finite water resources. In such cases, power differentials can be ameliorated via statutory or regulatory means.

TEQs is of particular interest in this light. Its basic design allows it to function both as a means of institutionally limiting fossil fuel pollution, and as an institutional response to mitigating inequities in access to supply-constrained fossil fuels. Moreover, TEQs is designed only to limit collectively-agreed social ills (reducing aggregate greenhouse gas pollution within an agreed emission budget, or reducing societal dependence on a supply-constrained essential resource, while in both cases ensuring equitable distribution of the costs). It is non-prescriptive with respect to the alternative social and economic pathways enacted in order to adapt to these limits. As such, it establishes an institutional context within which voluntary simplification has the opportunity to emerge as a viable alternative, without mandating that it be adopted. If it does emerge as a broad social movement, then this will be by collective choice, resulting from its recognition as a viable means of pursuing preferred futures.

The prospect of energy descent, discussed in Section 2, provides the backdrop against which we see the emergence of broader support for voluntary simplification as plausible. Indeed, in the absence of energy descent-if access to energy services continues instead to expand-then we concede that pursuit of 'sustainability' will continue in line with Tainter's model of problem-solving via socio-political complexification. At least, that is, until non-energetic constraints such as ecological collapse or supply-side limits for other critical resources take over. TEQs establishes an institutional context in which the question of energy abundance or sufficiency will be resolved.

From the viewpoint of orthodox policy and economic analysis, the expectation is that restricting the burning of fossil fuels will drive substitution of the associated energy from other sources, principally wind and solar PV, but also nuclear, and smaller shares from other renewables. However, if the collective will is established to self-limit the burning of fossil fuels, then TEQs provides the limiting mechanism and incentive structure for doing so, while remaining silent on what will substitute in its place. Effective functioning of TEQs is measured in terms of reduced fossil fuel use, regardless of the roles played by various supply- and demand-side responses in the substitution task. Under TEQs, fossil fuel consumers are in this sense free to proceed according to whatever non-fossil fuel alternative best meets their expectations for life satisfaction. They are equally free to pursue alternative expectations of life satisfaction, for instance, through voluntary simplification, as they are to pursue alternative energy sources in support of their existing expectations.

The question that remains, however, is why has TEQs received such meagre attention and support? This is not the forum to present a 'theory of change' $[17,63]$ or review the range of social, economic and political obstacles that lie in the way of TEQs being implemented. Nevertheless, we do acknowledge two primary obstacles. First, public recognition of the gravity of the overlapping challenges of fossil energy depletion, climate change and degradation of ecosystems remains poor. These issues are being discussed to varying degrees, of course, but the magnitude of the energetic predicament underlying a 
post-carbon transition is still marginalized and understated in mainstream discourse. This is partly due to a prevailing techno-optimism, which broadly assumes that technology, innovation, market mechanisms and better product design will resolve environmental problems (via 'green growth') without much in the way of reconfiguration of existing societal structures and cultural values [5]. If the prospect of energy descent or societal collapse is not clearly seen or its gravity appreciated, then there is little socio-cultural impetus to develop and implement coherent policy responses, such as TEQs. Promisingly, as this paper was under review, 100 prominent economists published an open letter in a mainstream newspaper calling for governments to actively phase out the fossil fuel industry [64]. Is TEQs an idea whose time might soon come? This is ultimately governed by political decision-making, and hence indeterminate. It does seem though that the ground is currently being laid for more widespread public discussion in which TEQs might be given serious consideration.

The second reason TEQs may be struggling to lay down roots in a policy context is a simple political reality: the 'powers that be'-especially corporations, their lobby groups, mass media and the nations and institutions doing well under the growth paradigm - have little incentive to transform a mode of societal organization that is (for the time being at least) offering them great rewards in terms of wealth and power. If TEQs is inconsistent with the interests of the dominant powers in the existing, globalized economic system, then perhaps it is no surprise that politicians and corporations and even those enamored with consumption-oriented ways of life, have little drive to deliberately induce, via TEQs, a paradigm shift in political economy in the direction of voluntary simplification. In short, despite the coherency of TEQs as a tool for managing energy descent, its implementation would depend on both a successful public relations campaign, and sustained socio-political will amongst advocates. However, none of that is likely to occur until energy descent is seen as a plausible future, and TEQs is seen as a coherent and even attractive policy for managing energy descent. It is that preliminary work to which this paper is intended to contribute.

\section{Conclusions: Navigating Energy Descent Pathways}

In this paper we contended that there are three primary and overlapping reasons for TEQs to be regarded as a policy mechanism highly suited to reducing fossil fuel dependency in a managed, timely and equitable way: (1) Fossil fuels are finite and have declining EROI, thus in the foreseeable future humanity will be forced to manage with reduced net energy availability from fossil energy sources; (2) Tight carbon budget targets strongly indicate that humanity must leave fossil fuels even before their depletion enforces a post-carbon transition and (3) Human energy use drives the transformation of the physical world that is degrading planetary ecosystems, suggesting that sustainable modes of production and consumption may involve creating very different forms of societal organization that are far less energy dependent. These three issues were discussed in relation to a further context of inquiry: the limits to non-carbon energy sources (RE in particular) delivering the range and scale of energy services upon which current societies depend. We outlined a case for why, when assessed with due epistemic humility, it is unlikely that RE sources will be able to fully replace the energy services provided by fossil fuels. All these reasons suggest that energy descent may lead to human futures shaped by energy sufficiency rather than energy abundance. We have presented TEQs as the most coherent policy for managing this turning point in globalized, industrial civilization.

Our novel contribution in this paper was to analyze TEQs in relation to Tainter's theory of societal complexity and collapse. As we have seen, Tainter argued that societies become more complex as they solve the range of problems they face, and that solving those problems demands increasing energy and other resources. When societies are unable to secure the resources needed to solve their problems, Tainter argues that they tend to undergo a process of involuntary simplification. In ordinary parlance, involuntary simplification means societal deterioration or even collapse, as more problems are faced that cannot be solved with a declining energy budget within existing modes of societal organization. Our approach was to theorize an alternative to collapse. Defending energy descent as a plausible energy future, we explored how, within Tainter's theory, a society could manage this 
energetic turning point without facing a collapse scenario. By analyzing the notion of voluntary simplification, we sought to show why an energy descent future need not imply societal collapse, although we did outline various ways in which managing energy descent would result in deep and diverse reconfigurations of fundamental modes of socio-political and economic organization. We employed the terms economic deintensification and degrowth as supplementary concepts to help explain what voluntary simplification would look like $[1,17]$. Our argument was that TEQs would help manage an energy descent future and that voluntary simplification and economic deintensification, leading to economic degrowth, would be required to avoid the collapse scenario otherwise inherent to Tainter's conceptual framework.

Much mainstream energy and sustainability discourse is based on a series of highly optimistic assumptions about future energy supply in a carbon-constrained world. The improbability of conditions aligning such that all necessary assumptions are borne out implies that the energy futures ahead will likely diverge significantly from those envisaged within this established discourse. This has potentially profound implications. The availability of energy in the right forms at sufficient rates is the lifeblood of any particular form of social organization. Energy-related factors are fundamental to how we shape our societies and pursue our goals, yet it seems most individuals and societies are making plans based on precarious expectations. One of the goals of the present analysis is to encourage readers to treat the prospect that these expectations will not be realized as, at the very least, a matter of plausibility.

In the event that mainstream expectations are thwarted, the consequences could range from the disruptive to the catastrophic. This is not a case against optimism, but rather of channelling it in directions that lie within humanity's scope of influence. Even within the difficult circumstances that our assessment implies, there is still much good that can be achieved. Ample room remains for adjusting expectations to better reflect underlying energy and environmental realities, and to reconstitute societies-and the economies that support them-accordingly. Dystopian interpretations of descent are not inherent in the concept itself; rather, they are an entailment of cultural priorities favouring continuous material and energetic expansion.

In closing, we appreciate the psychological drivers for denying the prospect of energy descent and trusting instead in a cornucopian or techno-optimistic worldview. It is less confronting to human identities and ways of life to believe that technology and markets can solve social and environmental problems without needing to rethink the underpinning structures that give rise to those problems. We posit that this means of coping with psychological dissonance, perhaps adaptive in other circumstances, is influential in the apparent 'self-censoring' (consciously or unconsciously) by mainstream energy and economic analysts, resulting in perspectives inconsistent with dominant economic and political paradigms being marginalized [26]. It would be preferable to believe and act upon what is most likely to be true following an honest and frank weighing of the evidence (supported by a robust public engagement campaign [65]). We have argued that this means coming to terms with the prospect of futures characterized by reduced access to energy services and creatively preparing for the socio-economic implications of energy descent by actively pursuing paths to deintensify economies, via strategies such as voluntary simplification.

All human societies exist interdependently with natural systems that are ultimately beyond human control. It is far preferable, we contend, that societies retain the greatest degree of agency possible in getting to grips with the dilemma of fossil fuel dependence. The alternative is to have our futures dictated to us by breakdown in natural systems that are beyond our capacity to control. TEQs offers a means for societies to manage the reduction in fossil fuel use in an orderly and coordinated way, so that citizens retain as much scope as possible for choosing the forms that their post-carbon futures might take.

Author Contributions: Conceptualization of review project, analysis, and argumentation, fundamentally collaborative. Section 1 up until Section 3.2, plus the conclusion, were originally drafted by S.A.; thorough review and editing by J.F.; From Section 3.2 to the conclusion were originally drafted by J.F.; thorough review and editing by S.A. All authors have read and agreed to the published version of the manuscript. 
Funding: This research received no external funding.

Conflicts of Interest: The authors declare no conflict of interest.

\section{References}

1. Fleming, D. Lean Logic: A Dictionary for the Future and How to Survive It; Chamberlin, S., Ed.; Chelsea Green Publishing: White River Junction, VT, USA, 2016.

2. IPCC. Summary for Policymakers. In Global Warming of $1.5^{\circ} \mathrm{C}$. An IPCC Special Report on the Impacts of Global Warming of $1.5^{\circ} \mathrm{C}$ above Pre-Industrial Levels and Related Global Greenhouse Gas Emission Pathways, in the Context of Strengthening the Global Response to the Threat of Climate Change, Sustainable Development, and Efforts to Eradicate Poverty; SR 1.5: Geneva, Switzerland, 2018.

3. Mohr, S.H.; Wang, J.; Ellem, G.; Ward, J.; Giurco, D. Projection of world fossil fuels by country. Fuel 2015, 141, 120-135. [CrossRef]

4. Bentley, R.W.; Mushalik, M.; Wang, J. The resource-limited plateau in global conventional oil production: Analysis and consequences. Biophys. Econ. Sustain. 2020, 5, 10. [CrossRef]

5. Hickel, J.; Kallis, G. Is green growth possible? New Political Econ. 2019, 25, 469-486. [CrossRef]

6. Floyd, J.; Alexander, S.; Lenzen, M.; Moriarty, P.; Palmer, G.; Chandra-Shekeran, S.; Foran, B.; Keyßer, L. Energy descent as a post-carbon transition scenario: How 'knowledge humility' reshapes energy futures for post-normal times. Futures 2020, 122, 102565. [CrossRef]

7. Steffen, W.; Richardson, K.; Rockström, J.; Cornell, S.E.; Fetzer, I.; Bennett, E.M.; Biggs, R.; Carpenter, S.R.; de Vries, W.; de Wit, C.A.; et al. Planetary boundaries: Guiding human development on a changing planet. Science 2015, 347, 1259855. [CrossRef]

8. Rockström, J.; Steffen, W.; Noone, K.; Persson, Å.; Chappin, F.S.I.; Lambin, E.; Lenton, T.M.; Scheffer, M.; Folke, C.; Schellenhuber, H.J.; et al. A safe operating space for humanity. Nature 2009, 461, $472-475$. [CrossRef]

9. Bringezu, S. Toward science-based and knowledge-based targets for global sustainable resource use. Resources 2019, 8, 140. [CrossRef]

10. Tainter, J.A. The Collapse of Complex Societies; Cambridge University Press: Cambridge, UK, 1988.

11. Tainter, J.A. Energy, complexity, and sustainability: A historical perspective. Environ. Innov. Soc. Transit. 2011, 1, 89-95. [CrossRef]

12. Tainter, J.A. Resources and cultural complexity: Implications for sustainability. Crit. Rev. Plant Sci. 2011, 30, 24-34. [CrossRef]

13. Homer-Dixon, T.; Walker, B.; Biggs, R.; Crépin, A.S.; Folke, C.; Lambin, E.F.; Peterson, G.D.; Rockström, J.; Scheffer, M.; Steffen, W.; et al. Synchronous failure: The emerging causal architecture of global crisis. Ecol. Soc. 2015, 20. [CrossRef]

14. Tainter, J.A. Sustainability of complex societies. Futures 1995, 27, 397-407. [CrossRef]

15. Bardi, U. Before the Collapse: A Guide to the Other Side of Growth; Springer: Singapore, 2020. [CrossRef]

16. Turner, G.M. Is a Sustainable Future Possible? J. Proc. R. Soc. New South Wales 2019, 152, 47-65.

17. Alexander, S.; Gleeson, B. Degrowth in the Suburbs: A Radical Urban Imaginary; Palgrave Macmillan: London, UK, 2019. [CrossRef]

18. Weiss, M.; Cattaneo, C. Degrowth-Taking stock and reviewing an emerging academic paradigm. Ecol. Econ. 2017, 137, 220-230. [CrossRef] [PubMed]

19. Alexander, S. Voluntary simplification as an alternative to collapse. Foresight 2014, 16, 550-566. [CrossRef]

20. Moriarty, P.; Honnery, D. Low-mobility: The future of transport. Futures 2008, 40, 865-872. [CrossRef]

21. Moriarty, P.; Honnery, D. The transition to renewable energy: Make haste slowly. Environ. Sci. Technol. 2011, 45, 2527-2528. [CrossRef]

22. Moriarty, P.; Honnery, D. Is there an optimum level for renewable energy? Energy Policy 2011, 39, $2748-2753$. [CrossRef]

23. Moriarty, P.; Honnery, D. Rise and Fall of the Carbon Civilisation: Resolving Global Environmental and Resource Problems; Springer: London, UK, 2011.

24. Moriarty, P.; Honnery, D. Can renewable energy power the future? Energy Policy 2016, 93, 3-7. [CrossRef]

25. Floyd, J. Sense-making and acting for descent futures: Human and cultural pathways. Foresight 2014, 16, 587-607. [CrossRef] 
26. Anderson, K. Duality in climate science. Nat. Geosci. 2015, 8, 898-900. [CrossRef]

27. The Simpler Way: Collected Writings of Ted Trainer; Alexander, S.; Rutherford, J. (Eds.) Simplicity Institute: Melbourne, Australia, 2020.

28. Ripple, W.J.; Wolf, C.; Newsome, T.M.; Galetti, M.; Alamgir, M.; Crist, E.; Mahmoud, M.I.; Laurance, W.F. World Scientists' warning to humanity: A second notice. BioScience 2017, 67, 1026-1028. [CrossRef]

29. Ripple, W.J.; Wolf, C.; Newsome, T.M.; Barnard, P.; Moomaw, W.R. World scientists' warning of a climate emergency. BioScience 2019, 70, 8-12. [CrossRef]

30. International Energy Agency. World Energy Outlook 2019; IEA: Paris, France, 2019.

31. International Energy Agency. Key World Energy Statistics 2019; International Energy Agency: Paris, France, 2019.

32. Harvey, D. A Brief History of Neoliberalism; Oxford University Press: Oxford, UK, 2005.

33. Hatfield-Dodds, S.; Schandl, H.; Adams, P.D.; Baynes, T.M.; Brinsmead, T.S.; Bryan, B.A.; Chiew, F.H.S.; Graham, P.W.; Grundy, M.; Harwood, T.; et al. Australia is 'free to choose' economic growth and falling environmental pressures. Nature 2015, 527, 49-53. Available online: http://www.nature.com/nature/journal/ v527/n7576/abs/nature16065.html\#supplementary-information (accessed on 15 August 2020). [CrossRef] [PubMed]

34. Energy Information Administration (EIA). International Energy Outlook; EIA: Washington, DC, USA, 2019.

35. Holmgren, D. Future Scenarios: How Communities Can Respond to Peak Oil and Climate Change; Chelsea Green Publishing: White River Jct, VT, USA, 2009.

36. Alexander, S.; Floyd, J. Carbon Civilisation and the Energy Descent Future: Life beyond this Brief Anomaly; Simplicity Institute: Melbourne, Australia, 2018.

37. Backhaus, K.; Gausling, P.; Hildebrand, L. Comparing the incomparable: Lessons to be learned from models evaluating the feasibility of Desertec. Energy 2015, 82, 905-913. [CrossRef]

38. Dudley, B. BP statistical Review of World Energy 2019; BP: London, UK, 2019.

39. Smil, V. Energy and Civilization: A History, Revised edition of: Energy in world history ed.; The MIT Press: Cambridge, MA, USA, 2017.

40. Miller, R.G.; Sorrell, S.R. The future of oil supply. Philos. Trans. R. Soc. A Math. Phys. Eng. Sci. $2014,372$. [CrossRef]

41. Murphy, D.J. The implications of the declining energy return on investment of oil production. Philos. Trans. R. Soc. A Math. Phys. Eng. Sci. 2014, 372. [CrossRef]

42. Fustier, K. Global Oil Supply: Will Mature Field Declines Drive the Next Supply Crunch?; HBSC Global Research Report: September 2016. Available online: https://www.ourenergypolicy.org/wp-content/uploads/ 2017/01/526500-1.pdf (accessed on 15 August 2020).

43. Michaux, S. Oil from a Critical Raw Material Perspective; Report 70/2019; Geological Survey of Finland: 2019. Available online: http://tupa.gtk.fi/raportti/arkisto/70_2019.pdf (accessed on 15 August 2020).

44. Emissions Gap Report 2019 Global Progress Report on Climate Action; UN Environment Programme: Nairobi, Kenya, 2019.

45. Anderson, K.; Broderick, J.F.; Stoddard, I. A factor of two: How the mitigation plans of 'climate progressive' nations fall far short of Paris-compliant pathways. Clim. Policy 2020, 1-15. Available online: https://www. tandfonline.com/doi/pdf/10.1080/14693062.2020.1728209?needAccess=true (accessed on 15 August 2020). [CrossRef]

46. Gabbattis, J. IEA: Coronavirus Impact on CO2 Emissions Six Times Larger than 2008 Financial Crisis. Available online: https://www.carbonbrief.org/iea-coronavirus-impact-on-co2-emissions-six-times-largerthan-financial-crisis (accessed on 7 July 2020).

47. Ward, J.D.; Sutton, P.C.; Werner, A.D.; Costanza, R.; Mohr, S.H.; Simmons, C.T. Is decoupling GDP growth from environmental impact possible? PLoS ONE 2016, 11, e0164733. [CrossRef]

48. Alexander, S. Sufficiency Economy: Enough, For Everyone, Forever; Simplicity Institute: Melbourne, Australia, 2015.

49. Valentine, S.V.; Sovacool, B.K.; Brown, M.A. Frame envy in energy policy ideology: A social constructivist framework for wicked energy problems. Energy Policy 2017, 109, 623-630. [CrossRef]

50. International Energy Agency. Key World Energy Statistics 2018; International Energy Agency: Paris, France, 2018. 
51. United Nations Department of Social and Economic Affairs. In World Population Prospects 2019: Highlights; United Nations: New York, NY, USA, 2019.

52. Laugs, G.A.H.; Moll, H.C. A review of the bandwidth and environmental discourses of future energy scenarios: Shades of green and gray. Renew. Sustain. Energy Rev. 2017, 67, 520-530. [CrossRef]

53. Allen, T.F.H.; Tainter, J.A.; Hoekstra, T.W. Supply-Side Sustainability; Columbia University Press: New York, NY, USA, 2003.

54. Tainter, J.A. Social complexity and sustainability. Ecol. Complex. 2006, 3, 91-103. [CrossRef]

55. Taleb, N.N. Antifragile: Things that Gain from Disorder; Random House: New York, NY, USA, 2012.

56. Homer-Dixon, T. The Upside of Down: Catastrophe, Conflict and the Renewal of Civilization; Alfred A Knopf: Toronto, ON, Canada, 2006.

57. Slaughter, R.A. The Biggest Wake Up Call in History; Foresight International: Indooroopilly, Australia, 2010.

58. Bardi, U. The Seneca Effect: Why Growth is Slow but Collapse is Rapid. A Report to the Club of Rome; Springer: Singapore, 2017.

59. Holmgren, D. RetroSuburbia: The Downshifter's Guide to a Resilient Future; Melliodora Publishing: Hepburn Springs, Victoria, Australia, 2018.

60. Nordberg-Hodge, H. Local is Our Future: Steps to an Economics of Happiness; Local Futures: 2019. Available online: https://www.localfutures.org/publications/local-is-our-future-book-helena-norberg-hodge/ (accessed on 15 August 2020).

61. Gibson-Graham, J.K.; Cameron, J.; Healy, S. Take Back the Economy: An Ethical Guide for Transforming our Communities; University of Minnesota Press: Minneapolis, MN, USA, 2013.

62. Chamberlin, S.; Maxey, L.; Hurth, V. Reconciling scientific reality with realpolitik: Moving beyond carbon pricing to TEQs-An integrated, economy-wide emissions cap. Carbon Manag. 2014, 5, 411-427. [CrossRef]

63. Buch-Hansen, $\mathrm{H}$. The prerequisties for a degrowth paradigm shift: Insights from critical political economy. Ecol. Econ. 2018, 146, 157-163. [CrossRef]

64. Sachs, J.; Mazzucato, M.; Brown, C.; Reich, R.; Zucman, G. Letter from Economists: To Rebuild Our World, We Must End the Carbon Economy; The Guardian: London, UK, 4 August 2020.

65. Shaw, C.; Hurth, V.; Capstick, S.; Cox, E. Intermediaries' perspectives on the public's role in the energy transitions needed to deliver UK climate change policy goals. Energy Policy 2018, 116, 267-276. [CrossRef] 